\title{
The Case for Selective Use of Pre-Operative Chemotherapy for Hepatic Colorectal Metastases: More Is Not Always Better
}

\author{
Giorgos Karakousis and Yuman Fong \\ Memorial Sloan-Kettering Cancer Center, New York, NY
}

The last two decades have seen great improvements in the treatment of hepatic colorectal metastases. The 1990s saw the maturation of data firmly establishing surgical resection as an effective and potentially curative therapy for this once uniformly fatal disease. ${ }^{1,2}$ In the last decade, introduction of systemic treatments such as oxaliplatin, irinotecan, bevacizumab, and cetuximab have added to favorable outcomes by increasing the number of patients eligible for resection, as well as by decreasing recurrence. ${ }^{3}$ Fifteen to $20 \%$ of patients with previously unresectable disease now have disease that is downstaged routinely by effective chemotherapy to a resectable state. ${ }^{3}$ On the basis of these data, oncologists in the United States have extended the preoperative use of chemotherapy to include not only those patients with unresectable disease (downstaging strategy), but also those patients with initially resectable disease (neoadjuvant strategy). The article in this issue by Reddy et al. is part of a growing body of data indicating that such liberal use of prehepatic resection chemotherapy may not be justified. ${ }^{4}$

Many theoretical justifications have been provided for the routine use of neoadjuvant chemotherapy (Table 1). These include the following: (1) Use of preoperative chemotherapy allows in vivo chemosensitivity determination by observing the response of tumors not yet resected (2) The additional waiting period allows distant disease to be established as unresectable for cure (3) The preoperative chemotherapy may produce better outcomes by treating undetectable disease early on (4) The period of chemotherapy treatment may allow patients after recent colectomy ample time to recover before a hepatic resection.

(C) Society of Surgical Oncology 2009

Published Online: 10 June 2009

Y. Fong

e-mail: fongy@mskcc.org
It turns out that only the last may be substantiated by the data. Because $72 \%$ of patients respond to cetuximab and FOLFOX chemotherapy and another $23 \%$ may have stable disease, it is the unusual patient $(5 \%)$ who experiences disease progression while receiving first-line therapy. ${ }^{5}$ In a recent study of perioperative chemotherapy, only $7 \%$ experienced progression of disease. ${ }^{6}$ Another article in the current issue demonstrates the progression of disease in only $10 \%$ of patients who receive neoadjuvant chemotherapy. ${ }^{7}$ The waiting period did little to identify patients with systemic disease because only 4 of 182 patients experienced an increase in number or sites of tumors, which would rule out resection. ${ }^{6}$ Thus, it is only after failure of first-line therapy that the concept of in vivo chemosensitivity testing makes sense. With improvements in identifying molecular predictors of response, resection early, on with thorough interrogation of the tissues, will probably prove to be a better strategy for choosing among chemotherapies. For example, one of the most important recent discoveries in the field was the finding that tumor analysis for K-ras mutation status can be used as a reliable predictor of response to cetuximab and oxaliplatin. ${ }^{8}$

Moreover, there is increasing evidence that preoperative chemotherapy may have substantial detrimental effects. The syndrome of chemotherapy-associated steatohepatitis is now well recognized. ${ }^{9}$ This syndrome is characterized by steatosis, splenomegaly, and thrombocytopenia-results of liver damage and portal hypertension. The clinical implications of such tissue damage on complications and postoperative recovery after liver resection are increasingly being reported. ${ }^{10}$ Given that, to date, no trial has clearly proven a role for preoperative chemotherapy, such neoadjuvant use of chemotherapy should not be regarded as the standard of care.

What should surgeons do now? If the patient has synchronous primary and metastatic disease that can be safely removed in the same operation, a combined resection is 
TABLE 1 Rationale for use of preoperative chemotherapy in patients with liver metastases

\begin{tabular}{|c|c|c|}
\hline Rationale & Justification & Evidence against \\
\hline \multicolumn{3}{|l|}{$\begin{array}{l}\text { As an attempt to downstage } \\
\text { patients for resection }\end{array}$} \\
\hline $\begin{array}{l}\text { To increase number of patients } \\
\text { eligible for resection }\end{array}$ & $\begin{array}{l}15-20 \% \text { of disease is converted to } \\
\text { resectable } ;^{3} \text { long-term survival of patients } \\
\text { documented after resection }\end{array}$ & \\
\hline \multicolumn{3}{|l|}{$\begin{array}{l}\text { As neoadjuvant therapy for } \\
\text { resectable disease }\end{array}$} \\
\hline $\begin{array}{l}\text { To perform in vivo } \\
\text { chemosensitivity testing }\end{array}$ & $\begin{array}{l}\text { Determines chemotherapy to use after } \\
\text { resection }\end{array}$ & $\begin{array}{l}\text { Less than } 10 \% \text { will progress on first-line cetuximab and } \\
\text { FOLFOX } ;^{5} \text { produces liver-related toxicities, and } \\
\text { detrimentally changes outcome of liver resection }{ }^{10}\end{array}$ \\
\hline $\begin{array}{l}\text { To allow distant disease to } \\
\text { manifest }\end{array}$ & $\begin{array}{l}\text { Avoids liver resection in those who will } \\
\text { not benefit }\end{array}$ & $\begin{array}{l}\text { Fewer than } 2 \% \text { of patients progressed outside the liver in the } \\
\text { waiting period; }{ }^{6} \text { there is increasing evidence that resection } \\
\text { of the liver may be beneficial even in patients with small- } \\
\text { volume disease outside the liver }\end{array}$ \\
\hline $\begin{array}{l}\text { To allow treatments of and } \\
\text { possible eradication of } \\
\text { microscopic disease }\end{array}$ & $\begin{array}{l}\text { The smaller the tumor volume, the more } \\
\text { likely it is to be cured by chemotherapy }\end{array}$ & $\begin{array}{l}\text { No trial has shown the use of preoperative chemotherapy to } \\
\text { improve long-term outcome over postoperative } \\
\text { chemotherapy alone }\end{array}$ \\
\hline $\begin{array}{l}\text { To allow patients to recover from } \\
\text { colectomy/proctectomy before } \\
\text { liver resection }\end{array}$ & $\begin{array}{l}\text { Many patients have weight loss and } \\
\text { debilitation post-surgery. In particular, } \\
\text { patients with complications from the } \\
\text { colectomy/proctectomy may fall into this } \\
\text { category }\end{array}$ & \\
\hline
\end{tabular}

justified. ${ }^{11}$ If the primary colorectal cancer has been removed, a delay in resection of synchronous secondaries may be justified by the need to recover from the primary resection. Such use of chemotherapy before subsequent liver resection is particularly attractive for patients with extensive regional nodal metastases or positive margins on the primary tumor resection.

The data in Reddy et al. show that a complete course of chemotherapy after liver resection is beneficial. ${ }^{4}$ What is unknown is whether postoperative chemotherapy was found to be useful because it was given in an uninterrupted course. Thus, an interesting trial for patients who have had the primary cancer removed but still had synchronous liver metastases in place is one randomizing these patients to 6 continuous months of chemotherapy before liver resection, versus treating them with 2 to 3 months of chemotherapy followed by resection and then adjuvant therapy. For patients with metachronous metastases, preoperative chemotherapy is only currently justified if disease is borderline or unresectable. All others should undergo resection followed by adjuvant chemotherapy except in the setting of trials.

What is the adjuvant therapy of choice? Accumulated evidence supports the notion that adjuvant therapy after liver resection is beneficial. Both randomized trials and retrospective data indicate that systemic 5-fluorouracil/ leucovorin (5-FU/LV) improves outcome. ${ }^{12,13}$ Extrapolation of data from stage III colorectal cancer would indicate that FOLFOX chemotherapy would also be a reasonable regimen. Thus, if the patient has not previously received chemotherapy, both 5-FU/LV and FOLFOX regimens are justified. Trials comparing these two regimens in the adjuvant setting are still needed. More controversy exists for those with disease that has failed to respond to first-line adjuvant therapy. Molecular profiles of the tumors, in particular K-ras mutations, will help guide the choice of second-line therapies in the future. Patients whose disease has failed to respond to FOLFOX or FOLFIRI are often placed on irinotecan/cetuximab or Xeloda/bevacizumab regimen, but this treatment is based on few data, and it generates costs of up to $\$ 100,000$ for a 6-month course. Such patients should be entered onto available trials or registries to accurately define the effects of such treatments. Although these agents have greatly improved outcomes in colorectal cancer, their precise role in offering cost-effective clinical benefits remains to be seen. Development of other effective therapies and other assays predicting response are priorities for research in this field.

\section{REFERENCES}

1. Fong Y, Sun RL, Jarnagin W, Blumgart LH. An analysis of 412 cases of hepatocellular carcinoma at a Western center. Ann Surg. 1999;229:790-9.

2. Fong Y, Fortner J, Sun RL, Brennan MF, Blumgart LH. Clinical score for predicting recurrence after hepatic resection for metastatic colorectal cancer: analysis of 1001 consecutive cases. Ann Surg. 1999;230:309-18. 
3. Adam R, Delvart V, Pascal G, et al. Rescue surgery for unresectable colorectal liver metastases downstaged by chemotherapy: a model to predict long-term survival. Ann Surg. 2004;240:644-57.

4. Reddy S, Zorzi D, Lum YW, et al. Timing of multimodality therapy for resectable synchronous colorectal liver metastases: a retrospective multi-institutional analysis. Ann Surg Oncol. DOI: 10.1245/s10434-008-0181-y.

5. Tabernero J, Van CE, az-Rubio E, Cervantes A, et al. Phase II trial of cetuximab in combination with fluorouracil, leucovorin, and oxaliplatin in the first-line treatment of metastatic colorectal cancer. J Clin Oncol. 2007;25:5225-32.

6. Nordlinger B, Sorbye H, Glimelius B, et al. Perioperative chemotherapy with FOLFOX4 and surgery versus surgery alone for resectable liver metastases from colorectal cancer (EORTC Intergroup trial 40983): a randomised controlled trial. Lancet. 2008;371(9617):1007-16.

7. Nikfarjam M, Shereef S, Kimchi E, et al. Survival outcomes of patients with colorectal liver metastases following hepatic resection or ablation in the era of effective chemotherapy. Ann Surg Oncol. DOI:10.1245/s10434-008-225-3.

8. Bibeau F, Lopez-Crapez E, Di Fiore F, Thezenas S, Ychou M, Blanchard F, et al. Impact of Fc \{gamma $\}$ RIIa-Fc $\{$ gamma $\}$ RIIIa polymorphisms and KRAS mutations on the clinical outcome of patients with metastatic colorectal cancer treated with cetuximab plus irinotecan. J Clin Oncol. 2009;27(7):1122-9.

9. Fong Y, Bentrem DJ. CASH (chemotherapy-associated steatohepatitis) costs. Ann Surg. 2006;243:8-9.

10. Khan AZ, Morris-Stiff G, Makuuchi M. Patterns of chemotherapy-induced hepatic injury and their implications for patients undergoing liver resection for colorectal liver metastases. $J$ patobiliary Pancreat Surg. (in press).

11. Martin R, Paty P, Fong Y, et al. Simultaneous liver and colorectal resections are safe for synchronous colorectal liver metastasis. $J$ Am Coll Surg. 2003;197:233-41.

12. Park R, Gonen M, Kemeny N, et al. Adjuvant chemotherapy improves survival after resection of hepatic colorectal metastases: analysis of data from two continents. $J$ Am Coll Surg. 2007;204:753-61.

13. Portier G, Elias D, Bouche O, et al. Multicenter randomized trial of adjuvant fluorouracil and folinic acid compared with surgery alone after resection of colorectal liver metastases: FFCD ACHBTH AURC 9002 trial. J Clin Oncol. 2006;24:4976-82. 